\title{
A faculty-led solution to transport-related stress among South African medical students
}

\author{
S Schoeman, ${ }^{1} \mathrm{MB}$ ChB, MMEd, PhD; G van Zyl, ${ }^{2} \mathrm{MB}$ ChB, PG Dip in Health Administration and Community Health, MFamMed, MBA, PhD; \\ R A Smego (deceased), ${ }^{3} \mathrm{MD}, \mathrm{MPH}, \mathrm{FACP}, \mathrm{FRCP}, \mathrm{DTM} \& \mathrm{H}$
}

${ }^{1}$ Department of Internal Medicine, Faculty of Health Sciences, University of the Free State, Bloemfontein, South Africa

${ }^{2}$ Office of the Dean, Faculty of Health Sciences, University of the Free State, Bloemfontein, South Africa

${ }^{3}$ School of Medicine, Faculty of Health Sciences, University of the Free State, Bloemfontein, South Africa

Corresponding author: S Schoeman (schoemanfhs@ufs.ac.za)

Background. In many parts of the developing world the lack of consistent and affordable transport may be a serious obstacle to education and a unique sociocultural cause of stress among undergraduate students.

Objective. To determine the student-perceived benefits of a faculty-led, grassroots student transport service for economically disadvantaged medical students. The service has been newly developed and implemented at the School of Medicine, University of the Free State, Bloemfontein, South Africa. Methods. A brief qualitative questionnaire survey, with Likert scales and free text, was administered to participants in the Student Transport Project after its first 21 months of operation. Students' views of the impact and effect of the project on their circumstances were surveyed.

Results. During its first 2 years of operation, the Student Transport Project was used by 116 students in their clinical third - fifth years, representing $16.6 \%$ of students in these years of training. All the participating students using the shuttle service were from previously disadvantaged communities and were economically disadvantaged. A survey among the participating students yielded an $84 \%$ response rate; they all felt that the service significantly reduced their levels of financial and emotional stress, and many believed that the project positively impacted on their academic performance and assisted them in remaining in medical school.

Conclusion. The basic, but novel, student transport service described in this article can have a dramatic effect in reducing medical student stress and, potentially, improving academic performance and success. It is hoped that others in lesser-developed countries in Africa and beyond may replicate such a student-centred transport initiative at their schools.

Afr J Health Professions Educ 2015;7(2):170-175. DOI:10.7196/AJHPE.352

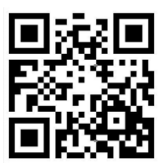

Stress among medical students is a universal cross-cultural phenomenon with many risk factors. ${ }^{[1-12]}$ Causes of stress include exogenous, endogenous, academic and non-academic factors. Stress and distress among medical students may lead to physical, psychological and academic difficulties; damaging effects on empathy, ethical conduct, and professionalism; personal consequences such as substance abuse, broken relationships, and suicidal ideation; and also contribute to burnout and dropout. ${ }^{[13-15]}$ Examples of institutionally provided medical student support services directed at reducing stress include counselling, wellness programmes, cognitive behavioural approaches, and peer mentor programmes. ${ }^{[16-18]}$ Transport challenges were recently highlighted as a major source of stress among medical and allied healthcare students. ${ }^{[19]}$

In this article we describe the lack of personal transport as a major and prevalent sociocultural cause of stress among underprivileged South African (SA) medical students. Furthermore, we present our practical experience and offer some financial information with regard to developing and implementing a student transport service for economically disadvantaged medical students at the University of the Free State (UFS), Bloemfontein, SA. It is hoped that other medical schools may find the data and information helpful to replicate a similar student-centred transport initiative aimed at alleviating financial and emotional pressures, which may have a positive effect on medical students' academic performance. We used 'underprivileged' and 'economically disadvantaged' interchangeably and defined these terms as a student group who, compared with their privileged or economically advantaged class peers with adequate financial means to enable easy access to private transport (a car), is forced to use the costly, untimely and dangerous public transport system in our city to commute between the hospitals of our training platform.

Before the inception of this project, underprivileged students without access to private transport had to rely on expensive, untimely and sometimes dangerous public minibus taxis to commute between the five different clinical sites of the UFS medical school training platform. During the preproject needs analysis, students reported that their annual cost to use public minibus taxis solely for their medical training needs was between ZAR5 000 and ZAR5 500. This led to undue and added financial, emotional and academic stress owing to the additional logistical pressures. Many of them were struggling to cope with the academic demands of their medical studies. Virtually all of the participating economically disadvantaged students have bursaries; hence, they have very little money left to pay for out-of-pocket expenses of local taxi transport. Some students reported that they often had to decide between affording the cost of travelling and having a meal.

\section{Institutional background}

The 110-year-old UFS is 1 of 24 public universities in SA, of which 8 (including the UFS) have medical schools. With its 8 faculties (including Health Sciences, comprising schools of Medicine, Nursing, and Allied Health Professions), 3 campuses, and $>31000$ students, including $>720$ medical students, UFS is one of the oldest institutions of higher learning in SA.

The School of Medicine (SoM) is situated on the main UFS campus in Bloemfontein, the capital city of the Free State Province. The SoM has a 5-year 
undergraduate medical curriculum, a parallel language medium of instruction (Afrikaans and English streams of separate language instruction), and uses the 5 medium-to-large state teaching hospitals in the greater Bloemfontein area to deliver its clinical training. The university has a $64 \%$ black student body population, while the SoM had the following student body racial demographics during the implementation phase of the project: white or Indian (72\%), and black or coloured (28\%). The reasons for the difference in overall student racial profiles between the greater UFS and SoM are mainly due to the fixed ratio (50/50) and numbers of first-year students (140) enrolled annually into the medical programme's parallel-medium language classes (70 in each class) and the relative higher attrition rate of students in the English class. The Afrikaans instruction class is a predominantly white class, with some coloured (mixed race) students, whereas the English class is largely constituted of ethnically black African, Indian and coloured students, with some white students. Transport challenges and related stress were identified as a possible contributing factor to the higher attrition rate in the English class groups - this was a motivating factor to develop this project.

\section{Project description}

The project is housed in the SoM. The Phase III Committee, which administers the clinical phase of the $\mathrm{MB} \mathrm{ChB}$ (medical) programme, is the curricular committee that oversees the project under the leadership of the project's academic managers, operational lead (the first author), and chair of the Phase III Committee. Other project personnel include an administrative officer as secretary for the Phase III Committee. She also manages the project on a day-to-day basis and deals with all the related administrative matters. She reports to the academic project manager, and together they run the operational side of the project. Students wishing to use the service must complete and sign the project application and indemnity form before a semester ticket is issued. The cost of a semester ticket, which is heavily subsidised by corporate sponsors, is billed to the UFS student accounts system of the relevant student. This was an important step and a huge help from the university, because the billing method enables the bursary providers to cover the transport cost, as it is viewed as an official student expense. To keep the administrative load regarding tickets and access to the project manageable, students must commit for an entire semester. If they wish to leave or join the project during the semester, the cost of the ticket remains unchanged and no refunds are issued. This strategy has proven to be very successful, as it encourages students to make informed and well thought through decisions at the start of each semester with regard to joining or leaving the project, and discourages ad hoc users.

The project is funded from two sources: corporate donors and the participating students' bus ticket sales each semester. The start-up funds were provided by three corporate donors: Netcare, a national private healthcare provider, which donated the two vehicles ( ZAR600 000), PPS Financial Services, which gave a ZAR114 000 cash donation, and Pfizer (SA), which donated ZAR57 000.

The Student Transport Project began operating on 11 April 2011. It proved an instant success with regard to easing the transport concerns and problems of the students. It was officially launched on 30 September 2011, with local and national media invited. The students' elected representatives from each year group (third - fifth year) form part of the project's management team who keep in touch with their needs and provide feedback on the system. During 2011 and 2012, 59 and 57 students, respectively, were part of the project. Table 1 provides a breakdown of the numbers and percentages of the total annual cohort involved in the project. Although the project is open to all students in the clinical phase of the medical curriculum (final 2.5 years of the 5-year programme), all (100\%) of the students who enrolled for the project were in the English class and black African, Indian or coloured. Therefore, to date, all the students engaged in the project were from previously disadvantaged communities (under the previous Apartheid government) that had no access to private transport.

The cost of the service for students per semester was ZAR1 200 during 2011 (pro rata from April to June) and ZAR1 350 in 2012, which was billed to their individual student UFS accounts. The project team, with funds made available from the SoM Phase III Committee (ZAR24 000), had designated car ports erected for the buses to protect the vehicles from the weather during times when they are not in operation.

Students can hop on and off the bus at any of the hospitals en route. The shuttle service operates 7 days a week and on public holidays. The fourth- and fifth-year medical students use the shuttle during the entire academic year (January - November, i.e. first and second semesters). The third-year students join the clinical phase of their training (Phase III) in the second semester of their third year. Therefore, the project carries more students and makes more weekday trips in the second semester (third - fifth years) than in the first semester (fourth and fifth years only) of each academic year. Table 2

Table 1. Students involved in the Transport Project

\begin{tabular}{llllll}
\hline & \multicolumn{2}{c}{$\mathbf{2 0 1 1}$} & & \multicolumn{2}{c}{$\mathbf{2 0 1 2}$} \\
\cline { 2 - 3 } \cline { 5 - 6 } Academic year & $\boldsymbol{n}$ & Class cohort, \% & & $\boldsymbol{n}$ & Class cohort, \% \\
\hline Third & 23 & $19(23 / 119)$ & & 9 & $8(9 / 118)$ \\
Fourth & 23 & $21(23 / 107)$ & & 32 & $26(32 / 125)$ \\
Fifth & 13 & $11(13 / 121)$ & & 16 & $15(16 / 108)$ \\
Total & 59 & $17(59 / 347)$ & & 57 & $16(57 / 351)$
\end{tabular}

Table 2. Shuttle times for the UFS Student Transport Project

\begin{tabular}{llll}
\hline & Departs from UFS & Back at UFS & Shuttle, $\boldsymbol{n}$ \\
\hline First semester & & & \\
Weekdays & $06 \mathrm{~h} 15$ & $07 \mathrm{~h} 15$ & 1 \\
& $07 \mathrm{~h} 15$ & $08 \mathrm{~h} 30$ & 2 \\
& $12 \mathrm{~h} 00$ & $13 \mathrm{~h} 00$ & 2 \\
& $17 \mathrm{~h} 30$ & $18 \mathrm{~h} 30$ & 1 \\
& $22 \mathrm{~h} 30$ & $23 \mathrm{~h} 15$ & 1 \\
Weekends and public & $07 \mathrm{~h} 30$ & $08 \mathrm{~h} 30$ & 1 \\
holidays & $10 \mathrm{~h} 30$ & $11 \mathrm{~h} 10$ & 1 \\
& $22 \mathrm{~h} 30$ & $23 \mathrm{~h} 15$ & 1 \\
Second semester & & & \\
Weekdays & $06 \mathrm{~h} 15$ & $07 \mathrm{~h} 15$ & 1 \\
& $07 \mathrm{~h} 15$ & $08 \mathrm{~h} 30$ & 2 \\
& $11 \mathrm{~h} 00$ & $12 \mathrm{~h} 00$ & 1 \\
& $12 \mathrm{~h} 00$ & $13 \mathrm{~h} 15$ & 2 \\
& $17 \mathrm{~h} 30$ & $18 \mathrm{~h} 30$ & 1 \\
& $22 \mathrm{~h} 30$ & $23 \mathrm{~h} 15$ & 1 \\
& $07 \mathrm{~h} 30$ & $08 \mathrm{~h} 30$ & 1 \\
Weekends and public & $11 \mathrm{~h} 10$ & 1 \\
holidays & $10 \mathrm{~h} 30$ & $23 \mathrm{~h} 15$ & 1 \\
& $22 \mathrm{~h} 30$ & &
\end{tabular}


provides an illustration of trip times of the shuttle during the respective semesters. The two shuttles conducted 1021 trips in 2011 and 1596 in 2012. A trip is defined as one circle route from the UFS SoM building to the 5 affiliated teaching hospitals in the greater Bloemfontein area, and back to the SoM building.

There are 2 bus drivers who share the transport duties for 7 days a week. Their official work uniform consists of UFS polo shirts and name badges. There are two 15-seat passenger shuttles (minibuses) - both equipped with satellite tracking devices (installation cost ZAR7 000 and annually ZAR7 000 for licences) that provide information regarding the whereabouts of the buses at all times and $\log$ the information of every trip. Project data are kept on the tracking company's server for 6 years. The drivers were paid ZAR60 per completed trip in 2011. Their fee is raised annually in line with UFS inflation salary adjustments. The project's administrative manager receives a small monthly stipend for being 'on call' after hours if problems should arise. The total operational costs for the project in the 21 months of operation were ZAR386 640. The project ended in 2012 with a positive balance of approximately ZAR160 000, which provided sufficient operating capital to continue with the project into 2013.

The project also developed a standard operating procedure (SOP) for the 2 drivers (Appendix A). Copies signed by the drivers are kept on file. Students are also aware of the SOP, as it is placed on Blackboard, the school's educational management system. Keys to the buses are kept securely in a combination safe in the SoM when the buses are not in use. Because of the operating hours described in Table 1, the drivers have electronic access cards to enable them to enter the SoM building after hours to fetch and return the keys before and after each trip, respectively.

\section{Methods}

The students who took part in this research study signed consent forms so that the authors may use their data and publish the findings. The UFS Faculty of Health Sciences Ethics Committee approved the study (Ethics Committee No. ECUFS 33/2013).

The research questions for this study were: (i) How many students are using the Transport Project; and (ii) What was the perceived impact of the Transport Project on the participants of the project with regard to their finances, stress levels, academic performance and wellbeing?
We reviewed our project registration forms to calculate the number of students using the project annually and invited all of them to complete a simple and quick self-administered Likert-scale questionnaire to evaluate the impact and effect of the project. The students could also add some free text comments to elucidate their responses.

The survey (Appendix B) was circulated during December 2012 to the graduating fifthyear students $(n=16)$ and in the first semester of 2013 to the students involved in the project at that stage $(n=40)$. Therefore, a total of 56 student participants were invited to take part in the study.

\section{Results}

During its first 2 years of operation, the Student Transport Project was used by 116 students in their clinical years 3 - 5, representing 16.6\% of students in these years of training during 2011 2012 (Table 1). The response rate for this study (survey component) was $84 \%$ (47/56).

The results of the student survey of the perceived impact and effect of the project are shown in Table 3.

Table 4 reports on selected student testimonials with regard to the Student Transport Project during its first 21 months of operation.

\section{Discussion}

The project represents a student-centred, facultydriven grassroots initiative that developed as a result of a faculty-perceived student need. Although it is explicitly stated in the regulations of our medical programme that transport arrangements between the SoM and our various training platform hospitals are the responsibility of individual students, the faculty members at the UFS SoM recognised that many of the students do not have the personal financial means for transport costs. Hence, we see this project as an outflow of our social responsibility to support our economically disadvantaged students to succeed in medicine.

Within the first 21 months of operation, the Student Transport Project has become a notable and visible institutional success. It is available to clinical medical students who require it; however, it is not a personalised system for individual participants. The participating students' responses to the project have been overwhelmingly positive. The data from Tables 3 and 4 show that the Transport Project had a positive influence on their academic experience and performance. Furthermore, students reported that the service significantly reduced their levels of financial and emotional stress, and many believed that the project helped them to remain in the medical programme. The perception that faculty members in the SoM care about the welfare and difficult circumstances of many of the participating students was enhanced by the project (Tables 3 and 4), which is helpful for fostering positive staffstudent relationships in the medical school.

From Table 1 it is evident that only a subgroup of students use the service and that most students do not need the project to facilitate their

Table 3. Perceived impact of Transport Project

\begin{tabular}{|c|c|c|}
\hline $\begin{array}{l}\text { Statement } \\
\text { number }\end{array}$ & Rated statement & $\begin{array}{l}\text { Mean Likert scale } \\
\text { finding }^{*}(n=47)\end{array}$ \\
\hline 1 & $\begin{array}{l}\text { Overall, the Student Transport Project has positively influenced my } \\
\text { medical school experience. }\end{array}$ & $4.6 / 5$ \\
\hline 2 & $\begin{array}{l}\text { The Student Transport Project has helped alleviate financial pressures } \\
\text { for me. }\end{array}$ & $4.6 / 5$ \\
\hline 3 & $\begin{array}{l}\text { The Student Transport Project has helped alleviate emotional/ } \\
\text { psychological pressures for me. }\end{array}$ & $4.2 / 5$ \\
\hline 4 & $\begin{array}{l}\text { I feel that the Student Transport Project has had a positive impact on } \\
\text { my academic performance at UFS. }\end{array}$ & $4.1 / 5$ \\
\hline 5 & $\begin{array}{l}\text { I feel that the Student Transport Project has been a major factor in } \\
\text { allowing me to stay in medical school. }\end{array}$ & $3.7 / 5$ \\
\hline 6 & $\begin{array}{l}\text { I feel that the Department of Medicine is truly concerned for the } \\
\text { wellbeing and success of students. }\end{array}$ & $4.7 / 5$ \\
\hline 7 & $\begin{array}{l}\text { I believe that the Student Transport Project would not have been } \\
\text { created without the concern and support of the faculty in the } \\
\text { Department of Medicine. }\end{array}$ & $4.7 / 5$ \\
\hline
\end{tabular}


Table 4. A selection of individual student narratives on the impact and effect of the Transport Project

- This project helps us to have safe and reliable transport. This project is most valuable during the evening especially for the female students.

- This has been a great help to me and I just want to thank Internal Medicine Department, the dean and all the corporate sponsors for keeping this initiative going.

- Thank you very much for making our academic experience easier. We saw out serious previous struggle with transport and we were very worried.

- It is important to keep this transport project going because it is very important to people like us without cars and also makes us stress free.

- This project has helped me a lot with regards to participate at the hospital and also the lectures. I am always on time and I manage to prepare my work and patients on time. Thank you.

- This project has relieved a lot of pressure on me as a student, it is highly beneficial and important.

- The Transport Project has been very helpful, it wouldn't have been possible for some of us to travel between the hospitals. Thank you very much!!

- The Student Transport Project is a very helpful transport system to those with no personal transport. It is important that even in the upcoming generation the system stays in use.

- I was one of the students who used to use public minibus taxis and I really appreciate and am thankful every day that the project was started and continues. Thank you.

- Thank you very much for your efforts, I cannot imagine how I would have managed to go and come back from hospitals at night (23h00), really personally you have helped me a lot. Please no matter what, do not stop helping us, we really truly appreciate. Thank you once more.

- It has truly alleviated the stress and we've been able to safely travel between the faculty and hospital. It has especially helped us in regard of our evening calls that end at 23 h00.

- I don't have a car and the Transport Project has at least alleviated that stress because I no longer worry about how I will get to Pelonomi/National hospital. The amount we pay is very reasonable considering it's for 6 months. On Saturdays and Sundays, it will be nice if there was transport that leaves at 17 h 30 as well, as well as on public holidays. All in all, Transport Project is a real great help!!

- The staff of the Student Transport Project is very accommodating and concerned about our wellbeing. It is an absolute pleasure to work with them. The project has been a great help to a lot of us, especially financially. It is not a lot of us students who have cars and having the Transport Project - it takes some pressure off.

- I do not know how I would have worked without the Transport Project. Some of the time you finish working at 11 pm and you do not have money to call a private taxi. Also, we are very grateful for the shuttle drivers, they are very understanding when sometimes we are released late from the call they always wait for us. Thank you very much.

transport needs. Students who are not using the project presumably prefer to use their own cars or make use of 'lift-clubs' with fellow students. Both of these options are probably more expensive, as they are not subsidised by corporate donors, but they are more personalised and convenient. However, the SoM realises that this does not imply that they are without some of the same stressors (e.g. finances and academic pressures) that the project students experienced.

Although this study did not directly measure the number of students without access to routine private transport for their medical training needs, and given the negative aspects outlined in this article about the public transport system in Bloemfontein, the study does give a good indication of the percentage of senior medical students (16.6\%, Table 1$)$ in our medical school who are reliant on travel support to meet their medical training needs.

Student affairs and financial aid offices at medical schools typically provide a range of academic and personal support services designed to help students succeed; these may play a crucial role in aiding students to stay in the academic programme. In the developed world, one does not usually consider student transport as a significant source of student stress and hardship ${ }^{[6]}$ because of the ability of students to provide their own transport or the availability of adequate public transport. In much of the developing world, however, a lack of consistent or affordable transport may be a real obstacle to successful employment and education. ${ }^{[19]}$

As educators, our ultimate goal is the success of the medical students in becoming competent and caring physicians. Our efforts in curriculum development and student supervision and assessment are directed towards realisation of this goal. At times, however, the success of students becomes critically dependent on non-educational efforts that take place outside the classroom or clinical arena. The role of non-academic student supportive services is often overlooked when evaluating the educational success of students. The kind of basic, but novel, student transport service described in this article may be helpful in reducing medical students' stress and, potentially, improving academic performance, as suggested by the students' feedback in this research project.

Acknowledgement. We acknowledge the important role and support of our corporate partners towards this project and in assisting future medical doctors in southern Africa - Netcare; PPS Financial Services; and Pfizer (SA).

We also acknowledge the efforts and drive of the late Professor Raymond Smego junior to publish this article and make this project known to healthcare professionals. He sadly passed away in December 2012.

\section{References}

1. Jaffri N, Jaleel A. Stress level in medical students. J Coll Physicians Surg Pak 2012;22(6):416. [http://dx.doi. org/06.2012/JCPSP.416416]

2. Nuallaong W. Correlation between stressors and academic performance in second year medical students. J Med Assoc Thai 2011;94(Suppl 7):S81-S85.

3. Al-Dubai SA, Al-Naggar RA, Alshagga MA, Rampal KG. Stress and coping strategies of students in a medical faculty in Malaysia. Malays J Med Sci 2011;18(3):57-64.

4. Abdulghani HM, AlKanhal AA, Mahmoud ES, Ponnamperuma GG, Alfaris EA. Stress and its effects on medical students: A cross-sectional study at a college of medicine in Saudi Arabia. J Health Popul Nutr 2011;29(5):516-522. Koochaki GM, Charkazi A, Hasanzadeh A, Saedani M, Qorbani M, Marjani A. Prevalence of stress among Iranian medical students: A questionnaire survey. East Mediterr Health J 2011;17(7):593-598.

6. Dyrbye LN Harper W Durning SJ et al. Patterns of distress in US medical students. Med Tea 2011:33(10):834-839. 6. Dyrbye LN, Harper W, Durning SJ, ed L. Pas Gomathi KG, Ahmed S, Sreedharan J. Psychological health of first-year health professional students in a medical
university in the United Arab Emirates. Sultan Qaboos Univ Med J 2012;12(2):206-213. university in the United Arab Emirates. Sultan Qaboos Univ Med J 2012;12(2):206-213.

8. Baykan Z, Naçar M, Cetinkaya F. Depression, anxiety, and stress among last-year students at Erciyes University Medical School. Acad Psychiatry 2012;36(1):64-65.

9. Benbassat J, Baumal R, Chan S, Nirel N. Sources of distress during medical training and clinical practice: Suggestions for reducing their impact. Med Teach 2011;33(6):486-490.

10. Voltmer E, Kötter T, Spahn C. Perceived medical school stress and the development of behavior and experience patterns in German medical students. Med Teach 2012;34(10):840-847. [http://dx.doi.org/10.3109/0142159X.2012706339] 1. Fan AP, Kosik RO, Su TP, et al. Factors associated with suicidal ideation in Taiwanese medical students. Med Teach 2011;33(3):256-257

12. Nagpal SJ, Venkatraman A. Mental stress among medical students. Natl Med J India 2010;23(2):106-107. 13. Dyrbye LN, Shanafelt TD. Medical student distress: A call to action. Acad Med 2011;86(7):801-803. 


\section{Research}

14. Dyrbye LN, Power DV, Massie FS, et al. Factors associated with resilience to and recovery from burnout: A prospective, multi-institutional study of US medical students. Med Educ 2010;44(10):1016-1026. [http://dx.doi. org/10.1111/j.1365-2923.2010.03754.x]

15. Chang E, Eddins-Folensbee F, Coverdale J. Survey of the prevalence of burnout, stress, depression, and the use of supports by medical students at one school. Acad Psychiatry 2012;36(3):177-182.

16. Thomas SE, Haney MK, Pelic CM, Shaw D, Wong JG. Developing a program to promote stress resilience and self-care in first-year medical students. Can Med Educ J 2011;2(1):e32-e36.
17. Barker TA, Ngwenya N, Morley D, Jones E, Thomas CP, Coleman JJ. Hidden benefits of a peer-mentored 'Hospital Orientation Day': First-year medical students' perspectives. Med Teach 2012;34(4):e229-e235. 18. McGrady A, Brennan J, Lynch D, Whearty K. A wellness program for first year medical students. App Psychophysiol Biofeedback 2012;37(4):253-260. [http://dx.doi.org/10.1007/ s10484-012-9198-x]

19. Omigbodun OO, Odukogbe AA, Omigbodun AO, Yusuf OB, Bella TT, Olayemi O. Stressors and psychological symptoms in students of medicine and allied health professions in Nigeria. Soc Psychiatry Psychiatr Epidemio 2006;41(5):415-421. [http://dx.doi.org/10.1007/s00127-006-0037-3]

Appendix A. Standard Operating Procedures for shuttle DRIVERS

UFS School of Medicine Transport Project

Version 3. 1 August 2012 (valid for 1 year - August 2013)

1. Drivers must under NO circumstances deviate from the normal prescribed route. This exposes the shuttles to possible theft and hijackings. Shuttles are fitted with GPS tracking devices and checks are done regularly. Regarding the 23:00 drop-off, you may drop particular students who paid the extra 'home drop fee', close to their homes. The other students must be dropped on the prescribed route.

2. Drivers are to ENSURE that they themselves and ALL passengers wear seatbelts at all times when the shuttle is in operation.

3. Drivers must NEVER drive faster than $\mathbf{6 0} \mathbf{~ k m} / \mathbf{h}$, except if it is a case of extreme urgency and must report this to Mrs Nel or Dr Schoeman on the first working day after the incident.

4. Drivers MUST follow the road rules and drive politely and never drive recklessly or in a manner that causes discomfort to any passenger. Passengers are encouraged to report good and bad driving.

5. NEVER stop in the street to pick up or drop off a student.

6. Drivers must NEVER talk on their cell phones while driving the bus. Please ask a student to answer your phone. It's illegal to talk on a mobile phone and drive.

7. Drivers must log trip details in logbook before and after each trip.

8. The logbook and drivers rota are used to calculate remuneration on a monthly basis.

9. When no students arrive for the trip at the different pick-up points, park the bus and complete the log book. The Tracker system will indicate movement of the shuttle and remuneration will only be paid when the UFS pick-up route is completed.

10. Drivers must report damage to the shuttle immediately upon return to the faculty (next day if after hours) AND inspect vehicle before he takes responsibility for it, otherwise he will be held responsible.

11. Drivers MUST collect and replace the keys to the shuttles in the security safe provided by the project. Tags and codes to the safe must NEVER be shared with ANY other person outside of the project team (i.e. drivers and management team - Dr Schoeman and Mrs Nel).

12. Drivers MUST check the validity of students' tickets BEFORE admitting them on the shuttle.

13. Drivers must ensure the neatness of the interior of the shuttles and report to management if students are messy in the shuttles.

14. In case of a hi-jack, press the panic button if possible. Co-operate with the hi-jackers and do not put yourself or the passengers' (if any) lives in danger.

15. If you are suspicious of someone following you, try to get the licence plate number or description of the car and report it to the nearest police station.

16. Defer all students' special requests to Dr Schoeman or Mrs Nel.

17. An up-to-date list of all the students participating will be available in each shuttle.

\section{Regarding the petrol cards:}

18.1 The card may only be used for the vehicle identified on the card.

18.2 Please make use of the Bloemgate service outlet in Nelson Mandela Drive.

18.3 Always check that the card you receive back is yours.

18.4 Report a stolen or lost card immediately to Mrs Nel.

18.5 Check that the slip is printed clearly and give it to Mrs Nel who will file it.

\section{Please take note:}

Drivers who transgress these SOPs will be subject to disciplinary procedures and could face possible dismissal.

Signed: at on 20

Name and surname: Signature:

Dr F H S Schoeman: Admin officer 


\section{Research}

Appendix B. Student questionnaire about the Student Transport Project

SCHOOL OF MEDICINE

Key

$1=$ Strongly disagree $\quad 2=$ Disagree $\quad 3=$ Uncertain $\quad 4=$ Agree $\quad 5=$ Strongly agree

Student Transport Project survey

- Overall, the Student Transport Project has positively influenced my medical school experience

12345

- The Student Transport Project has helped alleviate financial pressures for me

12345

- The Student Transport Project has helped alleviate emotional/psychological pressures for me in relation to my medical studies

12345

- I feel that the Student Transport Project has had a positive impact on my academic performance at UFS

12345

- I feel that the Student Transport Project has been a major factor in allowing me to stay in medical school

12345

- I feel that the Department of Internal Medicine is truly concerned for the wellbeing and success of students

12345

- I believe that the Student Transport Project would not have been created without the concern and support of the academic staff in the Department of Internal Medicine

12345

Additional comments: 